ARTICLE

\title{
Deep long period volcanic earthquakes generated by degassing of volatile-rich basaltic magmas
}

Oleg Melnik', Vladimir Lyakhovsky², Nikolai M. Shapiro (10 ${ }^{3,4 凶}$, Natalia Galina ${ }^{3,4}$ \& Olga Bergal-Kuvikas (iD ${ }^{5}$

Deep long-period (DLP) earthquakes observed beneath active volcanoes are sometimes considered as precursors to eruptions. Their origin remains, however, unclear. Here, we present a possible DLP generating mechanism related to the rapid growth of gas bubbles in response to the slow decompression of over-saturated magma. For certain values of the gas and bubble content, the elastic deformation of surrounding rocks forced by the expanding bubbly magma can be fast enough to generate seismic waves. We show that amplitudes and frequencies of DLP earthquakes observed beneath the Klyuchevskoy volcano (Kamchatka, Russia) can be predicted by our model when considering pressure changes of $\sim 10^{7} \mathrm{~Pa}$ in a volume of $\sim 10^{3}-10^{4} \mathrm{~m}^{3}$ and realistic magma compositions. Our results show importance of the deep degassing in the generation of volcanic seismicity and suggest that the DLP swarms beneath active volcanoes might be related to the pulses of volatile-rich basaltic magmas rising from the mantle.

\footnotetext{
${ }^{1}$ Institute of Mechanics, Moscow State University, 1 Michurinskiy prospekt, 119192 Moscow, Russia. ${ }^{2}$ Geological Survey of Israel, 32 Yesha'ayahu Leibowitz st, 9692100 Jerusalem, Israel. ${ }^{3}$ Institut de Sciences de la Terre, Université Grenoble Alpes, CNRS (UMR5275), CS 40700, 38058 Grenoble Cedex 9, France. ${ }^{4}$ Schmidt Institute of Physics of the Earth, Russian Academy of Sciences, Bolshaya Gruzinskaya str., 10-1, 123242 Moscow, Russia. ${ }^{5}$ Institute of Volcanology and Seismology, FEB RAS, 9 Piip Boulevard, 683006 Petropavlovsk-Kamchatsky, Russia. ${ }^{凶}$ email: nikolai.shapiro@univ-grenoble-alpes.fr
} 
$\mathrm{D}$ eep Long Period (DLP) earthquakes occurring in middle to lower crust and uppermost mantle beneath volcanoes ${ }^{1-9}$ remain enigmatic and in some cases, are believed to have connection with magmatic activity. Similar to volcanic longperiod (LP) seismicity in general ${ }^{10}$, the DLP earthquake has been considered to be generated by rapid pressure variations within magmatic plumbing systems. Alternatively, the effect of thermal stresses within cooling magma bodies has been considered ${ }^{11}$. The cooling magma stalled beneath the crust can also generate DLP earthquakes by so called "second boiling" or repeated pressurization of volatiles exsolved through crystallization, as has been recently suggested for dormant hot-spot Mauna Kea volcano in

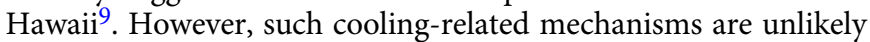
for DLP events occurring beneath active volcanoes in association with eruptions. Different possible origins of pressure variations resulting in LP seismicity have been considered ${ }^{12}$ including the unsteady magma motion, breaking of mechanical "barriers", 13, rapid degassing, etc. In any case, a reasonable model must provide a physical mechanism generating pressure variation $d P(t)$ consistent with observed seismic waves. This implies that the time scale of these variations must by rather short, i.e., comparable with typical frequencies/periods of seismic waves (e.g., $\sim 1$ s). Second condition is that the fluid pressure variation should be strong enough and well coupled with the elastic media. This coupling may imply resonances of fluid-filled cracks or cavities ${ }^{10}$ that under certain conditions can result in nearly monochromatic and very long duration signals. At the same time, such "strongly resonant" features are not observed for DLP signals that are characterized by rather short durations.

Here we propose that rapid changes of magmatic pressure near the crust-mantle boundary can be caused by nucleation and growth of gas bubbles in response to the slow decompression of over-saturated magma ${ }^{14}$. A volume of magma saturated with $\mathrm{H}_{2} \mathrm{O}-\mathrm{CO}_{2}$ volatiles is subjected to slow de-pressurization because of its slow upwelling. This magma first reaches the saturation level and then achieves the critical supersaturation after which the gas bubbles nucleate (Fig. 1a) and grow very fast (Fig. 1b). Fast expansion of the bubbly magma deforms the surrounding rocks which respond elastically on the time scale associated with the bubble growth and magma pressure variations. As a result of this elastic rock deformation, seismic waves are radiated (Additional information provided in Methods) and can be recorded by seismographs installed in vicinity of volcanoes.

The pressure variation in the bubbly magma is simulated using the model that accounts for multiple dissolved volatiles $\left(\mathrm{H}_{2} \mathrm{O}-\mathrm{CO}_{2}\right)$ and diffusive gas transfer from magma into the growing bubbles. It is based on the full solution of advectiondiffusion equation instead of quasi-static approach that was used before (Additional information provided in Methods) ${ }^{15}$. The bubble growth model is adopted to the case of bubble nucleation in basaltic magma ${ }^{16}$.

We compare the results of our modeling with DLP earthquakes observed beneath the Klyuchevskoy volcanic group (KVG) in Kamchatka, Russia. This volcanic group is one of the largest and most active clusters of subduction-zone volcanoes in the World ${ }^{17}$. KVG eruptions and their precursory periods are accompanied by sustained seismovolcanic activity including volcanic earthquakes $7,18,19$ and tremors ${ }^{20}$. We particularly focus on a persistent cluster of DLP earthquakes that occur in a small volume located at $\sim 30 \mathrm{~km}$ depth beneath the Klyuchevskoy volcano ${ }^{7,19,21}$. The moment magnitudes (Additional information provided in Methods) of these DLP events range between 1.1 and 2.5 with maximum of their distribution at 1.4 (Supplementary Fig. 1).

Initial data on volatiles in Klyuchevskoy ${ }^{22}$ suggested that primary magmas content $2.2-2.9$ wt.\% of water. Later, a detailed study of melt inclusions in olivines ${ }^{23}$ has shown that parental magma has $~ 3.5 \mathrm{wt} \% \mathrm{H}_{2} \mathrm{O}$ and $0.35-0.9 \mathrm{wt} \% \mathrm{CO}_{2}$. Large increase of water content for some melt inclusions (up to $7 \mathrm{wt} \% \mathrm{H}_{2} \mathrm{O}$ ) was explained by de-compressional crystallization, accumulation volatiles in the melt phase and consequent slow degassing 23,24 . However, recent experimental data shows that the volatile content of Klyuchevskoy magma is much larger than the one previously directly measured in melt inclusions due to coupled $\mathrm{SiO}_{2}-\mathrm{H}_{2} \mathrm{O}$ loss ${ }^{25}$, suggesting that primary magma may contain more than 4 wt $\%$ of $\mathrm{H}_{2} \mathrm{O}$. Single $\mathrm{H}_{2} \mathrm{O}$ volatile phase will result in a small saturation depth, but the addition of $\sim 0.6 \mathrm{wt} \%$ of $\mathrm{CO}_{2}$ increases volatile solubility dramatically so that magma becomes supersaturated at pressures of $800 \mathrm{MPa}(\sim 30 \mathrm{~km}$ depth $)$ that alternatively requires $\sim 10 \mathrm{wt} \%$ of pure $\mathrm{H}_{2} \mathrm{O}$.

We perform a parametric study to investigate the influence of volatiles content on the dynamics of bubble nucleation and growth. Our results show that the time scale of the bubble growth is mainly controlled by the gas and bubble content in the magma and under certain conditions can be sufficiently fast to generate seismic waves. In particular, we show that amplitudes and frequency content of DLP earthquakes observed beneath the Klyuchevskoy group of volcanoes can be predicted by our model when considering pressure changes of a few tens of $\mathrm{MPa}$ in a volume of $\sim 10^{3}-10^{4} \mathrm{~m}^{3}$ and magmas containing $\sim 4 \mathrm{wt} \%$ of $\mathrm{H}_{2} 0$ and $\sim 0.6 \mathrm{wt} \%$ of $\mathrm{CO}_{2}$. Our results provide evidence for the role of the deep degassing in the generation of long-period volcanic seismicity and suggest that the DLP swarms observed beneath active volcanoes
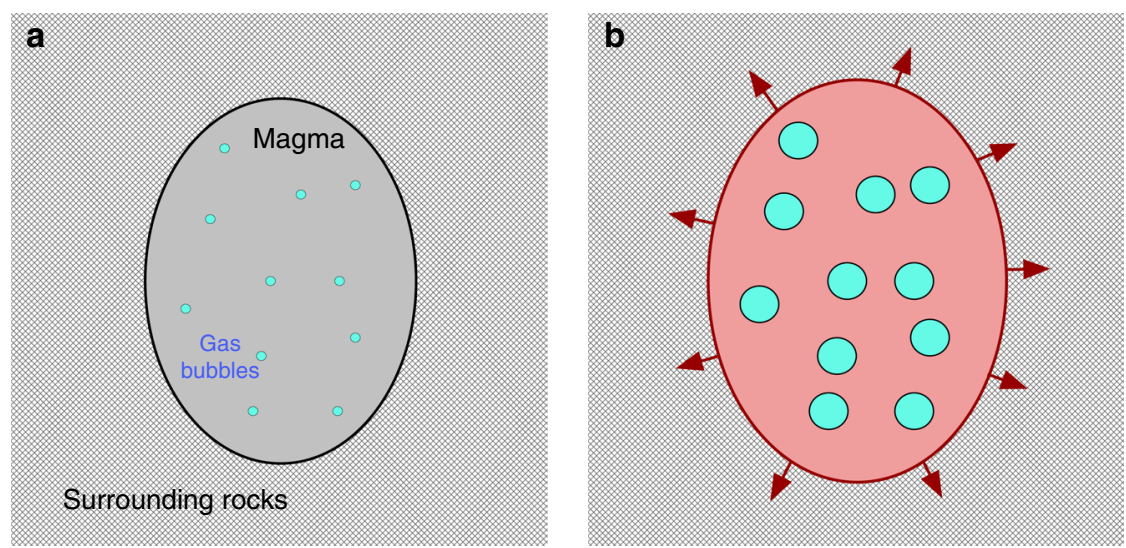

Fig. 1 Conceptual model of fluid-related source of long-period earthquakes. a Bubble nucleation in a volume of magma saturated with $\mathrm{H}_{2} \mathrm{O}-\mathrm{CO}_{2}$ volatiles. b Bubble and pressure growth deforming the surrounding rocks. 


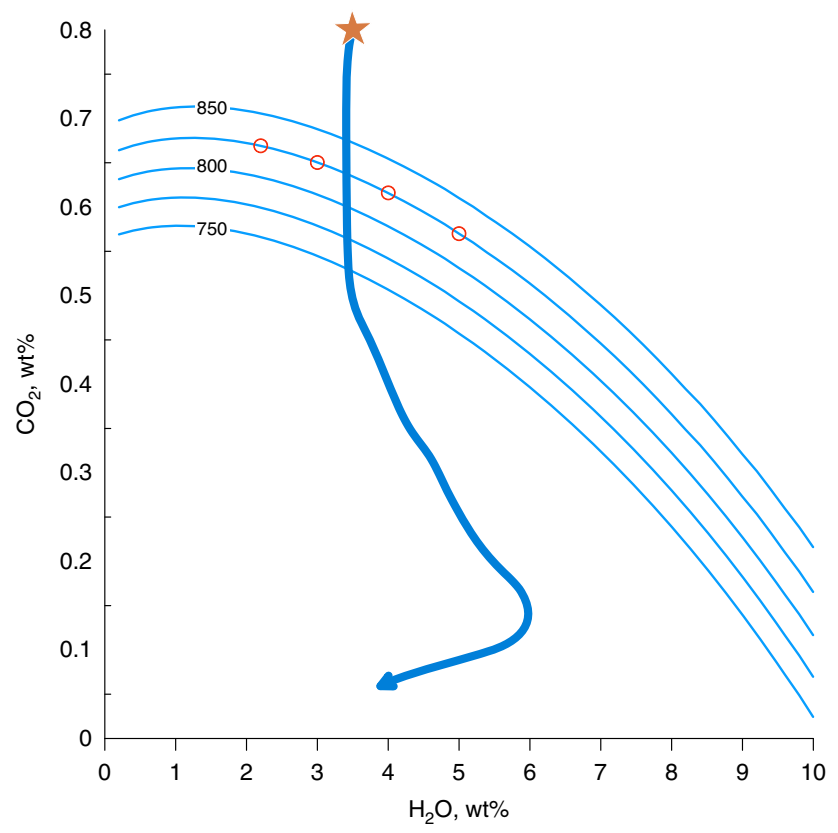

Fig. 2 Gas saturation isobars as function of $\mathrm{CO}_{2}-\mathrm{H}_{2} \mathrm{O}$ content. Thin blue lines show saturation isobars for different pressures (indicated values in $\mathrm{MPa}$ ). Thick solid line indicates the decompression path of the Klyuchevskoy magmas ${ }^{24}$ from initial state at $1 \mathrm{GPa}$ shown with a star. Red circles show compositions along the $828 \mathrm{MPa}$ isobar with $2,3,4$, and $5 \mathrm{wt} \%$ of $\mathrm{H}_{2} \mathrm{O}$ tested with numerical modeling (results shown in Fig. 3 ).

might be related to the pulses of fresh $\mathrm{CO}_{2}-\mathrm{H}_{2} \mathrm{O}$ rich basaltic magmas rising from the mantle.

\section{Results}

Volatiles content and the depth of degassing unset. Figure 2 shows how the solubility of the $\mathrm{CO}_{2}-\mathrm{H}_{2} \mathrm{O}$ mixture varies with pressure. Water and carbon dioxide concentrations were parametrized by polynomial functions of pressure and $\mathrm{CO}_{2}$ content in the bubble at a fixed temperature of $1230^{\circ} \mathrm{C}$ estimated from reversed crystallization of Klyuchevskoy melts from atmospheric conditions to $800 \mathrm{MPa}$ pressure (Additional information provided in Methods) and extrapolated to $1000 \mathrm{MPa}$ (Supplementary Table 1). The saturation point is reached at depths of the crustmantle transition $(\sim 30 \mathrm{~km} ; P \approx 825 \mathrm{MPa})$ for magmas with the volatile content typical for the Klyuchevskoy volcano, implying that degassing may start at such large depths.

Parameters controlling the time scale of bubble growth. Figure $3 \mathrm{a}, \mathrm{b}$ shows typical evolution of bubble size, gas and melt pressure in the basaltic magma with density ${ }^{26}$ of $2800 \mathrm{~kg} \mathrm{~m}^{-3}$, viscosity of $10 \mathrm{~Pa}$ and containing $10^{13}$ bubbles $\mathrm{m}^{-3}$ and for four different concentrations of $\mathrm{H}_{2} \mathrm{O}$ in initial magma. The $\mathrm{CO}_{2}$ contents (red circles in Fig. 2) were computed for initial pressure of $828 \mathrm{MPa}$ that corresponds to the lithostatic pressure at depth of $\sim 30 \mathrm{~km}$ for the average crustal density ${ }^{27}$ of $2830 \mathrm{~kg} \mathrm{~m}^{-3}$. Based on the experimental observations we adopt that the critical supersaturation for the bubble nucleation corresponds to the over-pressure of $\Delta P=40 \mathrm{MPa}^{14,28}$. This means that after nucleation the pressure in the gas bubble will be equal to its saturation value and the melt pressure is lower by $\Delta P$. Due to rapid bubble expansion gas pressure decreases extremely fast while melt pressure starts to increase as the volume of the magma increases. Initially gas pressure drop due to bubble expansion dominates pressure increase due to volatile influx into the growing bubble. After reaching minimum value $P_{\mathrm{g}}$ starts to increase, concentration gradients in the melt become smoother and volatile flux decreases. At later stages of the growth the difference between melt and gas pressures becomes small and bubble growth is controlled by the diffusion of volatiles.

The water diffusion coefficient is $1-2$ orders of magnitude larger than the diffusion coefficient for $\mathrm{CO}_{2}$. Thus, larger water content of magma for a fixed pressure require smaller amount of dissolved $\mathrm{CO}_{2}$ and bubble during growth will suck more $\mathrm{H}_{2} \mathrm{O}$. Adding more water into initial magma results in $\mathrm{H}_{2} \mathrm{O}$ enriched gas and more vigorous bubble and pressure grows (Fig. 3 ). The effect of water content is enhanced even stronger in predicted seismograms (Fig. 3d) with $\mathrm{H}_{2} \mathrm{O}$ depleted magmas resulting in very weak signals. We compare amplitudes of synthetic seismograms computed for a magma source volume of 30,000 $\mathrm{m}^{3}$ (linear dimension of a few tens of meters) with a real seismogram (Fig. 3e) recorded during DLP earthquake with a magnitude $M_{\mathrm{W}} \approx 2$ at station LGN located nearly above the source region (Supplementary Fig. 1). Amplitudes and the frequency content (Fig. 3f) are reasonably well predicted with a model based on $4 \mathrm{wt} \%$ water in basaltic magma typical for the Klyuchevskoy volcanic group ${ }^{25}$.

We then perform a sensitivity study of several other parameters on the pressure evolution in the growing bubbles and resulting melt (Supplementary Fig. 2). Critical supersaturation $^{28}$ that is required for bubble nucleation does not change melt-pressure recovery time significantly but will affect the amplitude of the source signal. We consider the melt viscosity range $10-10^{5} \mathrm{~Pa} \mathrm{~s}^{29}$. If viscosity is smaller than some threshold its influence on resulting pressure is negligible. Only larger melt viscosities typical for more silica reach melts $\left(10^{5}\right.$ $\mathrm{Pa} \mathrm{s}$ ) introduce some delay in pressure recovery. We assume instantaneous bubble nucleation in the whole batch of magma (Additional information provided in Methods). Thus, the size of the cell from which the bubble is growing is controlled by bubble number density $(B N D)$. We consider the $B N D$ range ${ }^{30}$ between $10^{11}$ and $10^{15} \mathrm{~m}^{-3}$. Increase in $B N D$ results in smaller cell sizes as $S_{0} \sim B N D^{-1 / 3}$. Melt pressure grows faster for smaller $S_{0}$.

\section{Discussion}

While the presented comparison of the observed and modelpredicted seismograms (Fig. $3 \mathrm{~d}-\mathrm{f}$ ) is based on significant simplifications of the source (ignoring realistic geometry and possible resonant behavior ${ }^{10}$ ) and the propagation effects (ignoring attenuation and wave scattering ${ }^{31}$ ), it shows that the amplitudes and the spectral content of the DLP signals observed at the Klyuchevskoy volcanic group can be explained to the order of magnitude by the bubble nucleation and growth in basaltic magmas according to the performed numerical simulation (Fig. 3d-f). Results of the presented modeling show that in the $\mathrm{CO}_{2}-\mathrm{H}_{2} \mathrm{O}$ rich basaltic magmas the degassing starts at large depths and is vigorous enough to produce strong and rapid pressure variations that can generate seismic radiation with amplitudes and frequency content comparable with those observed by seismographs during DLP earthquakes. Our results suggest that the DLP swarms observed beneath active volcanoes might be related to the intensification of the deep degassing caused by pulses of fresh $\mathrm{CO}_{2}-\mathrm{H}_{2} \mathrm{O}$ rich basaltic magmas rising from the mantle. This mechanism supports that the DLP earthquakes are early seismic manifestations of activation of deep parts of the Klyuchevskoy volcano plumbing systems. Similar behavior might be expected in other open and very active volcanic systems (with adjusting the model parameters based on their magma compositions and volatile contents). At 

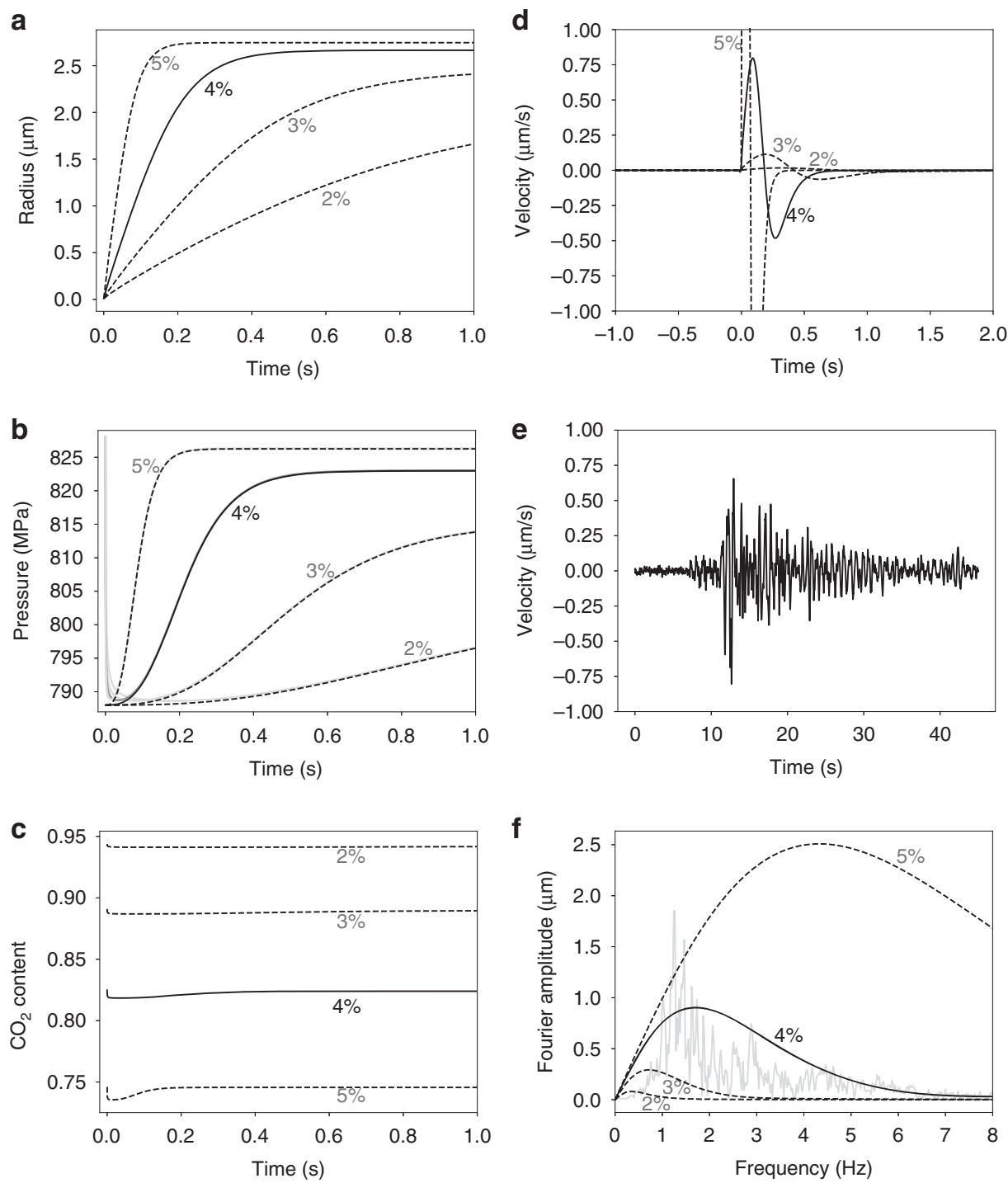

Fig. 3 Modeled dynamics of the bubble grows and magma pressure change. Results are shown for the bubble number density of $10^{13} \mathrm{~m}^{-3}$, four different water contents indicated with wt\% values in respective plots, and for $\mathrm{CO}_{2}$ content computed for $828 \mathrm{MPa}$ (red circles in Fig. 2). a Evolution of the bubble radius. $\mathbf{b}$ Evolution of magma pressure $P_{m}\left(P_{g}\right.$ values are shown with gray lines). c Evolution of the $\mathrm{CO}_{2}$ content in bubbles. $\mathbf{d}$ Ground velocities estimated for a source located at a $30 \mathrm{~km}$ distance from the receiver (Additional information provided in Methods). e Example of real seismogram (east-west component at station LGN, Supplementary Fig. 1). f Fourier amplitudes computed from synthetic and real (gray line) signals.

the same time, magma-cooling-related DLP mechanisms can dominate beneath nearly closed or dormant volcanoes.

One of the key features of our model is that the depth of occurrence of DLP earthquakes is related to the $\mathrm{CO}_{2}$ content in magmas. This is especially interesting considering that global volcanic $\mathrm{CO}_{2}$ fluxes in modern Earth remain poorly known ${ }^{32-38}$ and are often estimated indirectly based on $\mathrm{CO}_{2} / \mathrm{SO}_{2}$ or other ratio proxies, with direct $\mathrm{CO}_{2}$ observations at volcanoes being technically challenging. Our results suggest that studies of the DLP volcanic seismicity provide additional constraints on the magmatic $\mathrm{CO}_{2}$ content in the deep roots of volcanoes.

\section{Methods}

Mathematical model of gas bubble growth. We consider growth of an individual bubble in the center of a spherical cell of melt that expands with the bubble and supports it with volatiles. The spherically symmetric model includes equations of mass conservation of the melt in a cell Eq. (1), diffusion equations for volatiles $\left(\mathrm{H}_{2} \mathrm{O}-\mathrm{CO}_{2}\right)$ Eq. (2), Rayleigh-Lamb equation for bubble growth with negligibly small inertia terms and the equation for the melt pressure evolution due to expansion of the surrounding elastic host rock Eq. (3), mass balances for volatiles in the bubble Eq. (4), and equations that describe physical properties of the components Eq. (5):

$$
\begin{aligned}
& \frac{\partial}{\partial r}\left(r^{2} \nu_{r}\right)=0 ;\left.\nu_{r}\right|_{r=R}=\frac{d R}{d t} \\
& \frac{\partial c_{s}}{\partial t}+\nu_{r} \frac{\partial c_{s}}{\partial r}=\frac{1}{r^{2}} \frac{\partial}{\partial r}\left(D_{s} r^{2} \frac{\partial c_{s}}{\partial r}\right) ; s=C O_{2}(c), H_{2} O(w) \\
& P_{g}-P_{m}=\frac{2 \sigma}{R}+4 \mu \frac{d R}{d t}\left(\frac{1}{R}-\frac{R^{2}}{S^{3}}\right) ; P_{m}=P_{m}^{0}+\frac{4}{3} G\left(\frac{S^{3}-S_{0}^{3}}{S_{0}^{3}}\right) \\
& \frac{4 \pi}{3} \frac{d}{d t}\left(R^{3} \rho_{g} x_{\mathrm{CO} 2}^{b}\right)=4 \pi R^{2} J_{c} ; \frac{4 \pi}{3} \frac{d}{d t}\left(R^{3} \rho_{g}\left(1-x_{\mathrm{CO} 2}^{b}\right)\right)=4 \pi R^{2} J_{w} ; \\
& J_{c}=-D_{c} \rho_{m}\left(\frac{\partial c_{c}}{\partial r}\right)_{r=R} ; J_{w}=-D_{w} \rho_{m}\left(\frac{\partial c_{w}}{\partial r}\right)_{r=R} . \\
& \rho_{g}=\left(\frac{x_{\mathrm{CO} 2}^{b}}{\rho_{\mathrm{CO} 2}\left(P_{g}, T\right)}+\frac{1-x_{\mathrm{CO2}}^{b}}{\rho_{\mathrm{H} 2 \mathrm{O}}\left(P_{g}, T\right)}\right)^{-1} ; \\
& \rho_{\mathrm{CO} 2}=\left(0.371+0.13 \times 10^{-3} T\right) \cdot P_{g}+1194.65-0.4665 T ; \\
& \rho_{\mathrm{H} 2 \mathrm{O}}=\left(0.22+0.13 \times 10^{-3} \mathrm{~T}\right) \cdot P_{g}+892.2-0.357 \mathrm{~T} ; \\
& D_{w}=c_{w} \cdot \exp \left(-8.56-\frac{19110}{T}\right) ; \\
& D_{c}=\exp \left(-13.99-\frac{\left(17367+1.945 P_{g}\right)}{T}+\frac{c_{w} \cdot\left(855.2+0.271 P_{g}\right)}{T}\right)
\end{aligned}
$$


Here $t$ is time, $r$ is the radial coordinate, $R$ is the radius of the bubble, $v_{r}$ is the radial velocity, $c_{c}$ and $c_{w}$ are the mass concentrations of $\mathrm{CO}_{2}$ and $\mathrm{H}_{2} \mathrm{O}$ in the melt, $D_{c}$ and $D_{w}$ are the volatile diffusion coefficients ${ }^{39}, P_{g}$ is the pressure of the gas inside the bubble, $P_{m}$ is the melt pressure, $\sigma$ is the surface tension, $\mu$ is the magma viscosity, $S$ is the radius of the cell, $G$ is the shear modulus of the host rock, $\rho_{g}$ is the density of the gas in the bubble that depends on the pressure, temperature $T$ and bubble volatile composition $x_{\mathrm{CO} 2}^{b}$. The densities of pure $\mathrm{CO}_{2}\left(\rho_{\mathrm{CO} 2}\right)$ and $\mathrm{H}_{2} \mathrm{O}\left(\rho_{\mathrm{H} 2 \mathrm{O}}\right)$ are approximated at a limited P-T range using tables produced by NIST Chemistry WebBook (https://webbook.nist.gov/chemistry/).

Equation (2) is subjected to two boundary conditions: concentration gradients are equal to zero at the outer surfaces of the cell mimicking symmetry of the system. At $r=R(t)$ volatiles in magma are in chemical equilibrium with the bubble. Thus, $c_{s}=c_{s}^{e q}\left(p, T, x_{\mathrm{CO} 2}^{b}\right)$. We use D-compress software ${ }^{40}$ in order to calculate equilibrium concentrations.

The nucleation time of bubbles $t_{n}$ from a supersaturated melt is related to the bubble number density $B N D$ via the nucleation rate $I\left(\mathrm{~m}^{-3} \mathrm{~s}^{-1}\right): t_{n}=B N D / I$ According to classical nucleation theory ${ }^{41}, I$ increases extremely fast with oversaturation pressure $\Delta P: I \sim \exp \left(-1 / \Delta P^{2}\right)$. It depends on the temperature and a number of melt properties including surface tension, volume and concentration of water molecules in the melt, as well as distance between them, diffusion coefficient of volatiles at the bubble-melt interface, probability that a nucleus at the top of the barrier will go on to form the new phase, rather than dissolve (Zeldovich factor), and others. With a huge uncertainty of these parameters and difficulties in their experimental constrain, the estimated nucleation rate values vary by orders of magnitudes. For a basaltic melt with an overpressure about $40 \mathrm{MPa}$ a value of $I \sim$ $10^{26} \mathrm{~m}^{-3} \mathrm{~s}^{-1}$ has been suggested ${ }^{42}$. With this $I$-value, nucleation time for $B N D=$ $10^{13} \mathrm{~m}^{-3}$ (values preferred in our study) is $\sim 10^{-13} \mathrm{~s}$, which is many orders of magnitude below the typical time scale of the simulated bubble growth and of the observed periods of seismic waves $(\sim 1 \mathrm{~s})$. These estimations were obtained assuming that magma degassing is dominated by homogeneous nucleation. In the presence of crystals, their interfaces serve as a preferable location for the heterogeneous nucleation which takes roughly the same time, but produces significantly lower number of bubbles. In the case of heterogeneous nucleation, a pressure perturbation, induced by a limited number of new created bubbles, propagates through a magma-filled cavity providing a trigger for the homogeneous nucleation in the whole volume of magma. Such combination of heterogeneous and homogeneous nucleations is often assumed for many natural systems ${ }^{28}$. The duration of this process is controlled by a propagation time of a pressure pulse across a volume of over-saturated magma. With typical dimensions of a few tens of meters and sound speed being of the order of a few $\mathrm{km} / \mathrm{s}$, the combined heterogeneous and homogeneous nucleation will take less than 0.01 s, i.e., two orders of magnitude below typical bubble growth times. Therefore, we consider instantaneous nucleation in the whole volume.

Numerical method. Equation (1) can be integrated analytically and gives the following velocity distribution in the melt phase: $v_{r}=\frac{d R}{d t} \frac{R^{2}}{r^{2}}$. In order to solve Eq. (2) in a fixed domain we use front-fixing method ${ }^{43}$. A coordinate transformation $\xi=\frac{r-R(t)}{S(t)-R(t)}$ gives extra advective term in Eq. (2). The resulting equation is discretized on an irregular 1D mesh with a decrease of the step size towards the growing bubble boundary $(\xi=0)$. The resulting system of equations with threediagonal matrix is solved by means of Thomas algorith ${ }^{44}$. The forward step starts at the outer domain boundary $(\xi=1)$. The linear relation of volatile concentration on the bubble boundary and in the nearest mesh points together with discretized Eqs. (3) and (4) allows to calculate all parameters on the bubble-melt interface. Then, concentration distribution in the whole domain is calculated during backward substitution. We found this method stable and computationally efficient in comparison with explicit methods that require extremely small timesteps for stability reasons.

Estimation of magma composition. In order to estimate magma compositions in the deep magma reservoir we used "Petrolog" software ${ }^{45}$. Reverse crystallization from a more evolved magma (sample 12KY-108-1, $1987 \mathrm{AD}$ eruption ${ }^{46}$ ) was performed. The starting pressure is set to atmospheric level and magma is $\mathrm{H}_{2} \mathrm{O}$ saturated. Our simulations reveal total amount of mineral phase of $20 \%$ for the starting composition, which is in a good agreement with the measurements on the samples ${ }^{47}$. Incremental increase in pressure to $800 \mathrm{MPa}$ leads to the change in composition presented in Supplementary Table 1. These values were obtained considering the volatile component composed only of $\mathrm{H}_{2} \mathrm{O}$, resulting in a $800 \mathrm{MPa}$ magma containing almost $11 \mathrm{wt} \%$ of dissolved water. Adding even a small amount of $\mathrm{CO}_{2}$ affects significantly the water solubility that can be reduced to a few wt\% as shown in Fig. 2 along the $800 \mathrm{MPa}$ isobar. Based on data about Klyuchevskoy magma volatile content ${ }^{22-25,48}$, we retain for our modeling a composition with $\sim 4$ wt $\%$ of $\mathrm{H}_{2} \mathrm{O}$ and $\sim 0.6 \mathrm{wt} \%$ of $\mathrm{CO}_{2}$.

Estimation of magnitudes of deep low-frequency earthquakes. The DLP signals whose energy is concentrated in a narrow spectral band between 1 and $2 \mathrm{~Hz}$ are dominated by S-waves (Fig. 3e, f). The seismic moment can be approximately estimated from maximal signal amplitude in the following way. We start with an expression of the far-field (hypocenter distances exceeding 10 wavelengths) S-wave displacement ${ }^{49} u^{\mathrm{S}}$ and ignore the radiation pattern assuming that it approximately averages to 1 . Based on this we can relate the time derivative of seismic moment with the observed S-wave displacement:

$$
\dot{M}_{0}(t) \sim 4 \pi \rho \beta^{3} r \cdot u^{\mathrm{S}}(t)
$$

where $t$ is time $M_{0}$ is seismic moment, $\rho$ is density, $\beta$ is S-wave speed, and $r$ is the hypocentral distance. The observed ground velocity $v^{\mathrm{S}}$ is the derivative of the displacement that for a nearly monochromatic signal can be approximately estimated via multiplication by $2 \pi f^{\max }$ :

$$
v^{\mathrm{S}}(t) \sim \dot{u}^{\mathrm{S}}(t) \sim 2 \pi f^{\max } \cdot u^{\mathrm{S}}(t)
$$

where $f^{\max }$ is the dominant signal frequency. Integration of Eq. (6) to obtain the whole seismic moment can be also approximately estimated with dividing by $2 \pi f^{\text {max }}$. This leads to a final expression used to approximately estimate the seismic moment from one station:

$$
M_{0} \sim \frac{4 \pi \rho \beta^{3} r \cdot u^{\mathrm{s}}}{2 \pi f^{\max }}=\frac{\rho \beta^{3} r}{\pi f^{\max 2}}\left|v_{\max }^{\mathrm{s}}\right|
$$

where $v_{\max }^{\mathrm{s}}$ is the maximum amplitude of velocity seismograms (taking into account all three components). The final estimate is averaged from several stations that recorded the earthquake. We use $f^{\max }=1.5 \mathrm{~Hz}$ and typical crustal values for density $^{27}, \rho=2830 \mathrm{~kg} \mathrm{~m}^{-3}$, and seismic velocity ${ }^{50,51}, \beta=3500 \mathrm{~m} \mathrm{~s}^{-1}$. The moment magnitude $M_{W}$ is then computed as:

$$
M_{\mathrm{w}}=\frac{2}{3}\left(\lg \left(M_{0}\right)-9.05\right)
$$

Estimation of seismic radiation emitted by expanding magma volume. For simplicity, we start with considering a volume with a perfectly spherical shape embedded in an infinite elastic space with bulk modulus $K$. In response to the magma pressure change $d P(t)$, the volume will be modified by $d V(t)$ :

$$
d V(t)=\frac{d P(t) V}{K}
$$

For a perfectly spherical magma body, the volume change can be related to the seismic moment as ${ }^{49}$ :

$$
M_{o}(t)=K d V(t)=d P(t) V
$$

A spherically symmetric source would radiate in the far field only $\mathrm{P}$ waves. At the same time, signals from real DLP earthquakes are dominated by $S$ waves. A simple explanation of this observations can be related to the deviation of the magma body shape from a perfect sphere. In this case, the change of the magma pressure will induce a significant amount of shear stress in the surrounding rocks resulting in a strong S-wave radiation ${ }^{52}$. A possible example is a pure tensile crack mechanism for which the seismic moment tensor can be written $\mathrm{as}^{49}$ :

$$
M(t)=\left(\begin{array}{ccc}
\lambda d V(t) & 0 & 0 \\
0 & \lambda d V(t) & 0 \\
0 & 0 & (\lambda+2 \mu) d V(t)
\end{array}\right)
$$

where $\lambda$ and $\mu$ are Lamé constants that for most of elastic solids are nearly equal and have the same order of magnitude as bulk modulus $(K=\lambda+2 / 3 \mu)$ implying that to the order of magnitude the relationship (11) between seismic moment (observed amplitudes of waves), pressure variations, and volume of affected fluid remain valid. Seismic radiation from such source for many directions is dominated by S-waves ${ }^{53}$

At this stage, we do not consider detailed description of seismic radiation from a non-spherical source that would vary significantly depending on the exact magma volume shape. We rather make an order of magnitude estimation and consider that Eq. (11) describes the relationship between the magma pressure change and the seismic moment observed in the far field (hypocenter distances exceeding 10 wavelengths). Based on Eq. (6), the ground displacement can be expressed as:

$$
u(t) \approx \frac{\dot{M}_{0}(t)}{4 \pi \rho \beta^{3} r}=\frac{\dot{P}(t) V}{4 \pi \rho \beta^{3} r}
$$

and the ground velocity is computed as its time derivative.

\section{Data availability}

The seismological time series used for the analysis were provided by the Kamchatka Branch of the Geophysical Survey of Russian Academy of Sciences (GS RAS) and are available on request (http://www.emsd.ru). The data are not publicly available due to the internal regulation of the GS RAS.

Received: 5 March 2020; Accepted: 10 July 2020; Published online: 06 August 2020 


\section{References}

1. Pitt, A. M. \& Hill, D. P. Long-period earthquakes in the Long-Valley Caldera region eastern California. Geophys. Res. Lett. 21, 1679-1682 (1994).

2. White, R. A. in Fire and mud: eruptions and lahars of Mount Pinatubo, Philippines (eds Newhall, C. G. \& Punongbayan, R. S.) 307-326 (Univ. Washington Press, 1996)

3. Pitt, A. M., Hill, D. P., Walter, S. W. \& Johnston, M. J. S. Mid-crustal, longperiod earthquakes beneath northern California volcanic areas. Seismol. Res. Lett. 73, 144-152 (2002).

4. Power, J. A., Stihler, S. D., White, R. A. \& Moran, S. C. Observations of deep long-period (DLP) seismic events beneath Aleutian arc volcanoes; 1989-2002. J. Volcanol. Geotherm. Res. 138, 243-266 (2004).

5. Nichols, M. L., Malone, S. D., Moran, S. C., Thelen, W. A. \& Vidale, J. E. Deep long-period earthquakes beneath Washington and Oregon volcanoes. J. Volcanol. Geotherm. Res. 200, 116-128 (2011).

6. Aso, N., Ohta, K. \& Ide, S. Tectonic, volcanic, and semi-volcanic deep lowfrequency earthquakes in western Japan. Tectonophysics 600, 27-40 (2013).

7. Shapiro, N. M. et al. Deep and shallow long-period volcanic seismicity linked by fluid-pressure transfer. Nat. Geosci. 10, 442-445 (2017).

8. Hensch, M. et al. Deep low-frequency earthquakes reveal ongoing magmatic recharge beneath Laacher See Volcano (Eifel, Germany). Geophys. J. Int 216, 2025-2036 (2019).

9. Wech, A. G., Thelen, W. A. \& Thomas, A. M. Deep long-period earthquakes generated by second boiling beneath Mauna Kea volcano. Science 368, 775-779 (2020).

10. Chouet, B. A. Long-period volcano seismicity: its source and use in eruption forecasting. Nature 380, 309-316 (1996).

11. Aso, N. \& Tsai, V. C. Cooling magma model for deep volcanic long-period earthquakes. J. Geophys. Res. 119, 8442-8456 (2014).

12. Chouet, B. A. \& Matoza, R. S. A multi-decadal view of seismic methods for detecting precursors of magma movement and eruption. J. Volcanol. Geotherm. Res. 252, 108-175 (2013).

13. Shapiro, N. M., Campillo, M., Kaminski, E., Vilotte, J. -P. \& Jaupart, C. Lowfrequency earthquakes and pore pressure transients in subduction zones. Geophys. Res. Lett. 45, 11,083-11,094 (2018).

14. Lensky, N. G., Niebo, R. W., Holloway, J. R., Lyakhovsky, V. \& Navon, O. Bubble nucleation as a trigger for xenolith entrapment in mantle melts. Earth Planet. Sci. Lett. 245, 278-288 (2006).

15. Lyakhovsky, V., Hurwitz, S. \& Navon, O. Bubble growth in rhyolitic melts: experimental and numerical investigations. Bull. Volcanol. 58, 19-32 (1996).

16. Gonnermann, H. M. \& Manga, M. Nonequilibrium magma degassing: results from modeling of the ca. $1340 \mathrm{AD}$ eruption of Mono Craters, California. Earth Planet. Sci. Lett. 238, 1-16 (2005).

17. Shapiro, N. M. et al. Understanding Kamchatka's extraordinary volcano cluster. EOS 98, https://doi.org/10.1029/2017eo071351 (2017).

18. Senyukov, S. L. Forecasting of the eruptions of volcanoes Klyuchevskoy and Bezymianny at Kamchatka [in Russian] (Lambert Academic, 2013).

19. Senyukov, S. L. et al. Studies in the activity of Klyuchevskoi volcano by remote sensing techniques between January 1, 2001 and July 31, 2005, Volcanol. Seismol 3, 50-59 (2009).

20. Droznin, D. V. et al. Detecting and locating volcanic tremors on the Klyuchevskoy group of volcanoes (Kamchatka) based on correlations of continuous seismic records. Geophys. J. Int. 203, 1001-1010 (2015).

21. Gorelchik, V. I., Garbuzova, V. T. \& Storcheus, A. V. Deep-seated volcanic processes beneath Klyuchevskoi volcano as inferred from seismological data. J. Volcanol. Seismol. 6, 21-34 (2004).

22. Khubunaya, S. A. \& Sobolev, A. V. Primary melts of calc-alkaline magnesian basalts from Klyuchevskoy Volcano, Kamchatka, Dokl. Akad. Nauk 360, 100-102 (1998).

23. Portnyagin, M., Hoernle, K., Plechov, P., Mironov, N. \& Khubunaya, S. Constraints on mantle melting and composition and nature of slab components in volcanic arcs from volatiles $\left(\mathrm{H}_{2} \mathrm{O}, \mathrm{S}, \mathrm{Cl}, \mathrm{F}\right)$ and trace elements in melt inclusions from the Kamchatka Arc. Earth Planet. Sci. Lett. 255, 53-69 (2007).

24. Mironov, N. L. \& Portnyagin, M. V. $\mathrm{H}_{2} \mathrm{O}$ and $\mathrm{CO}_{2}$ in parental magmas of Kliuchevskoi volcano inferred from study of melt and fluid inclusions in olivine. Russian Geol. Geophys. 52, 1353-1367 (2011).

25. Portnyagin, M. et al. Dehydration of melt inclusions in olivine and implications for the origin of silica-undersaturated island-arc melts. Earth Planet. Sci. Lett. 517, 95-105 (2019).

26. Stolper, E. \& Walker, D. Melt density and the average composition of basalt. Contrib. Mineral. Petrol. 74, 7-12 (1980).

27. Christensen, N. I. \& Mooney, W. D. Seismic velocity structure and composition of the continental crust: A global view. J. Geophys. Res. Solid Earth 100(B6), 9761-9788 (1995).

28. Shea, T. Bubble nucleation in magmas: a dominantly heterogeneous process? J. Volcanol. Geotherm. Res. 343, 155-170 (2017).

29. Shaw, H. R. Viscosities of magmatic silicate liquids; an empirical method of prediction. Am. J. Sci. 272, 870-893 (1972).
30. Sable, J. E., Houghton, B. F., Del Carlo, P. \& Coltelli, M. Changing conditions of magma ascent and fragmentation during the Etna $122 \mathrm{BC}$ basaltic Plinian eruption: evidence from clast microtextures. J. Volcanol. Geotherm. Res. 158 333-354 (2006).

31. Aki, K. \& Chouet, B. Origin of coda waves: source, attenuation, and scattering effects. J. Geophys. Res. 80, 3322-3342 (1975).

32. Allard, P. et al. Eruptive and diffuse emissions of $\mathrm{CO}_{2}$ from Mount Etna. Nature 351, 387-391 (1991)

33. Edmonds, M. New geochemical insights into volcanic degassing. Philos. Trans R. Soc. A 366, 4559-4579 (2008).

34. Burton, M. R., Sawyer, G. M. \& Granieri, D. Deep carbon emissions from volcanoes. Rev. Mineral. Geochem. 75, 323-354 (2013).

35. Hartley, M. E., Maclennan, J., Edmonds, M. \& Thordarson, T. Reconstructing the deep $\mathrm{CO}_{2}$ degassing ehavior of large basaltic fissure eruptions. Earth Planet. Sci. Lett. 393, 120-131 (2014).

36. Kelemen, P. B. \& Manning, C. E. Reevaluating carbon fluxes in subduction zones, what goes down, mostly comes up. Proc. Natl Acad. Sci. USA 112, E3997-E4006 (2015).

37. Taran, Y. et al. Gas emissions from volcanoes of the Kuril Island arc (NW Pacific): geochemistry and fluxes. Geochem. Geophys. Geosyst. 19, 1859-1880 (2018)

38. Aiuppa, A. et al. $\mathrm{CO}_{2}$ flux emissions from the Earth's most actively degassing volcanoes, 2005-2015. Sci. Rep. 9, 5442 (2019).

39. Zhang, Y., Ni, H. Diffusion of H, C, and O Components in Silicate Melts. Reviews in Mineralogy and Geochemistry. 72, 171-225 (2010).

40. Burgisser, A., Alletti, M. \& Scaillet B. D-Compress https://vhub.org/resources/ 3791 (2015).

41. Hirth, G., Pound, G. M. \& St Pierre, G. R. Bubble nucleation. Metall. Trans. 1 939-945 (1970).

42. Navon, O. \& Lyakhovsky, V. Vesiculation processes in silicic magmas. Geol. Soc., Lond. Spec. Pub 145, 27-50, https://doi.org/10.1144/GSL. SP.1996.145.01.93 (1998).

43. Crank, J. Free and moving boundary problems (Oxford Science Publications, 1987).

44. Mooney, D. D. \& Swift, R. J. A course in mathematical modeling (Cambridge University Press, 1999).

45. Danyushevsky, L. V. \& Plechov, P. Petrolog3: Integrated software for modeling crystallization processes. Geochem. Geophys. Geosyst. 12, Q07021 (2011).

46. Bergal-Kuvikas, O. et al. A petrological and geochemical study on time-series samples from Klyuchevskoy volcano, Kamchatka arc. Contrib. Mineral. Petrol. 172, 35 (2017).

47. Bergal-Kuvikas, O. Geochemical studies of volcanic rocks from the northern part of Kuril-Kamchatka arc: tectonic and structural constraints on the origin and evolution of arc magma. Doctoral dissertation. P.190. (Hokkaido University, 2015)

48. Auer, S., Bindeman, I., Wallace, P., Ponomareva, V. \& Portnyagin, M. The origin of hydrous, high-delta O-18 voluminous volcanism: diverse oxygen isotope values and high magmatic water contents within the volcanic record of Klyuchevskoi volcano, Kamchatka, Russia. Contrib. Mineral. Petrol. 157, 209-230 (2009).

49. Aki, K. \& Richards, P. G. Quantitative seismology (University Science Books, 2002).

50. Levin, V., Droznina, S., Gavrilenko, M., Carr, M. J. \& Senyukov, S. Seismically active subcrustal magma source of the Klyuchevskoy volcano in Kamchatka, Russia. Geology 42, 983-986 (2014).

51. Droznina, S. et al. S-wave velocity model for several regions of the Kamchatka Peninsula from the cross correlations of ambient seismic noise. Izvestiya Phys. Solid Earth 53, 341-352 (2017)

52. Eshelby, J. D. The elastic field outside an ellipsoidal inclusion. Proc. R. Soc. A 252, 561-569 (1959).

53. Shi, Z. \& Ben-Zion, Y. Seismic radiation from tensile and shear point dislocations between similar and dissimilar solids. Geophys. J. Int 179, 444-458 (2009)

\section{Acknowledgements}

We thank Yuri Taran, Patrick Allard, Roberto Moretti, and Daniel Neuville for helpful discussions as well as Brian Shirofor his very helpful revision of the manuscript. This study was supported by the Russian Ministry of Education and Science (Grant no. 14 W03.31.0033), and by the European Research Council (ERC) under the European Union Horizon 2020 Research and Innovation Programme (Grant agreement 787399-SEISMAZE).

\section{Author contributions}

O.M. and V.L. designed the model of the gas bubble grows in the magma and made the computation. N.S. participated in the discussion of the model design and analyzed seismological observations. N.G. analyzed seismological observations. O.B. analyzed the composition of the Klyochevskoy basaltic magmas. All of the authors contributed to interpretation of the data, discussions of the results, and preparation of the manuscript. 


\section{Competing interests}

The authors declare no competing interests.

\section{Additional information}

Supplementary information is available for this paper at https://doi.org/10.1038/s41467020-17759-4

Correspondence and requests for materials should be addressed to N.M.S.

Peer review information Nature Communications thanks Brian Shiro and the other, anonymous, reviewer(s) for their contribution to the peer review of this work.

Reprints and permission information is available at http://www.nature.com/reprints

Publisher's note Springer Nature remains neutral with regard to jurisdictional claims in published maps and institutional affiliations. (c) (i) Open Access This article is licensed under a Creative Commons Attribution 4.0 International License, which permits use, sharing, adaptation, distribution and reproduction in any medium or format, as long as you give appropriate credit to the original author(s) and the source, provide a link to the Creative Commons license, and indicate if changes were made. The images or other third party material in this article are included in the article's Creative Commons license, unless indicated otherwise in a credit line to the material. If material is not included in the article's Creative Commons license and your intended use is not permitted by statutory regulation or exceeds the permitted use, you will need to obtain permission directly from the copyright holder. To view a copy of this license, visit http://creativecommons.org/ licenses/by/4.0/.

(C) The Author(s) 2020 